\title{
Conserving for the Future by Archiving our Past; A Story about Technology and Digitization Informed by a Vintage Paperback Book Collection \\ By Cybèle Werts
}

\begin{abstract}
:
The books, photographs, letters and other ephemera of our past are for the first time becoming completely transformed into the digital bits and bytes of our computer-generated present. What happens to these products as they shift from the corporeal to the technological world? What essence might be lost when a book is scanned into a computer or is part of the Google Book Library Project, and what might be gained? Or is it all energy simply transferred to another medium like when wood is burned in a fireplace turns into to heat energy? This extended article explores these questions using a collection of vintage magazines and paperback books, which provide a lighthearted timbre to a somewhat esoteric subject.
\end{abstract}

\section{Navigating this Information}

The goal of this article is to look at what occurs in the process of transforming products from an analog format (actual items like books) to a digital one (scanned graphics). This is not a how-to guide to scanning or developing databases, however, it is a discussion of the considerations around archiving and digitization as they are utilized today. It is important to know what is gained and lost as products change from one form to another, and how to make the best of that process.

To illustrate these concepts, the article includes graphics from a collection of vintage magazines and paperbacks, which provides a sense of what happens to an actual group of historical items going through this process, and what choices conservators have along the way. This includes some of the issues around scanning, digital cameras, and airbrushing and how these relate to authenticating documents on the internet. This collection will be used to specifically discuss conservation and what happens to collections that are online in one format versus another. A little background and history on vintage materials is also included.

\section{Part I: Beginning the Process of Digitizing Introduction}

In 2008, a special year for information specialists, the organization that has represented librarians for one hundred years - The Special Libraries Association -celebrated its centennial birthday. Whenever there comes a big moment, it is natural to look back to our history and forward to our future. After all, it is a familiar reminder that those who forget their past are destined to repeat it."

Those who work with information however, are far less likely to forget the past, if only because, they also recognize the value of the archivable past more than the average person. Librarians know how to care for both the old world of ephemera (things that are temporary - or ephemeral" - in nature) as well as in the contemporary world where these same objects are transformed into data. Data may seem ephemeral on the surface, but can and does live forever on the Internet.

If there are any doubts about the half life of data on the Internet, consider how one accidentallyposted piece of information be repeated ad infinitum from one website to the next, with no way to ever correct or even catch up with the speed of proliferation. Or consider how people have posted photos, blogs, or other material which presumably seemed at the time to be -personal," but later turned out to be incriminating in ways they could not even have imagined. This is particularly true on the internet where photos, videos, and audio clips can be duplicated a thousand times before they are able to remove" the offending material, at least from the original context.

\section{Ephemera: Analog versus Digital}

Most librarians are probably familiar with what happens when they make copies of a copy and the

Education Libraries, Volume 33, Number 2, Winter 2010 
quality decreases with each generation. This Generation Loss only happens with actual physical objects like a book or an old fashioned record; or what are called analog" products. On the other hand, -digital" is commonly used as a descriptor in relation to compact disks, and of course computers as well. Music records are analog (making a copy to cassette tape or CD, creates a generation loss), but CDs are digital (creating a hundred copies to iTunes causes no loss whatsoever, other than a relative amount of what is called dynamic range). The reason why no generation loss occurs is because digital objects are made up of zeros and ones, each one being independent of the next. They can be replicated easily, over and over. Just as a side note, the word here is analog, not analogue. The word analogue refers to a literary work that shares motifs, characters or events with another, but is not directly derived from it (think analogous).

The short version is that ephemera as a group of materials are analog. If an old fashioned record was scratched, the scratch would be heard every few seconds as the turntable rotates, bumping over the imperfection again and again (remember: continuous $=$ analog). On the other hand, a similar scratch would likely not have the same effect on a compact disk and there would likely be no change in the sound. This is because the recorded values are stored far enough beneath the surface that the scratch does not affect them. A loss of sound could be discerned however, if perhaps a cat scratched the $\mathrm{CD}$, which would result in a chunk of a song being lost. But it still won"t "skip" in the way records used to. This is because the CD -scratch" disturbed bits of information that were not contiguous. (remember: not contiguous $=$ digital).

\section{What happens to Ephemera when It Gets Scanned?}

The formal definition of Ephemera includes paper items like books, magazines, letters, photographs, ticket stubs, advertising, and so on. Take a few vintage paperback book covers for example, some of which have been converted to digital format for this article. In looking at them, it can be observed that in the process of being scanned, they become in a way, sanitized. What that means is that they look clean, bright and new; pretty much the opposite of what they actually are. Nothing that is fifty-plus years old looks clean, bright, and new in real life. In a way, it cannot be helped. The samples here have the advantage of having been scanned professionally, meaning that they were scanned using professional equipment and software. Despite that advantage, many details are lost because of the small size on the page, as well as the fact that these pictures are viewed in two dimensions, while actual magazines and books are, of course, three-dimensional.

\section{Scanning and Generation Loss}

The temporary aspect of ephemera refers to objects made of paper which generally have a short shelf life, and which when copied - as mentioned earlier - cause a generation loss. Why does this matter? Well, it is something to keep in mind when developing a protocol for dealing with whatever paper objects that will be scanned. For example, when choosing an object to scan, always choose the very best copy of the product at hand. The collection may include several copies of a particular book, often because one copy was purchased less expensively, and then was later upgraded to a higher quality version; higher quality, perhaps because the printing registration was better. Registration has to do with how the printer lays each layer of color down. If the registration is off, then the color won't fit between the lines; it makes the cover look a little peculiar. In a case like this be sure to scan the best version available. Similarly, always scan the original of a photograph or book cover, never a photocopy even if it looks as good as the ones produced from a high-end color printers.

\section{Digital Cameras for 3-D}

Another option to digitize an object is to use photography instead of a scanner. Photographs yield far more information about size, condition, and other features because they can show the condition of the spine, depth of the book, and details about the deterioration around the edges. A scanner on the other hand, is flat, so the

Education Libraries, Volume 33, Number 2, Winter 2010 
information it receives is only a two-dimensional side, like the front cover of a book. Photography is optimal when working with items like a pop-up children's book, documents that are designed to open up in a certain way, or those which have more depth than a scanner can show effectively, like a framed picture.

The challenge is that taking photographs of products is more difficult than it sounds; and in fact there is an entire professional field dedicated to product photography. In addition, digital cameras - easy as they appear in commercials can be challenging for amateurs who don't know the basics of graphic design. Scanners are generally far easier to use as most of them are more or less -elick and go."

\section{Issues around Airbrushing}

Airbrushing images, or what is called in the graphic design world Photoshopping" (after the software application Photoshop), makes pictures look far more perfect than they actually are. There's a sample of this in the Future Science Fiction magazine sample below, and it suggests how airbrushing done with ulterior motives might mislead a viewer. This particular scan was cleaned up in just five minutes, and the visual impact is significant.

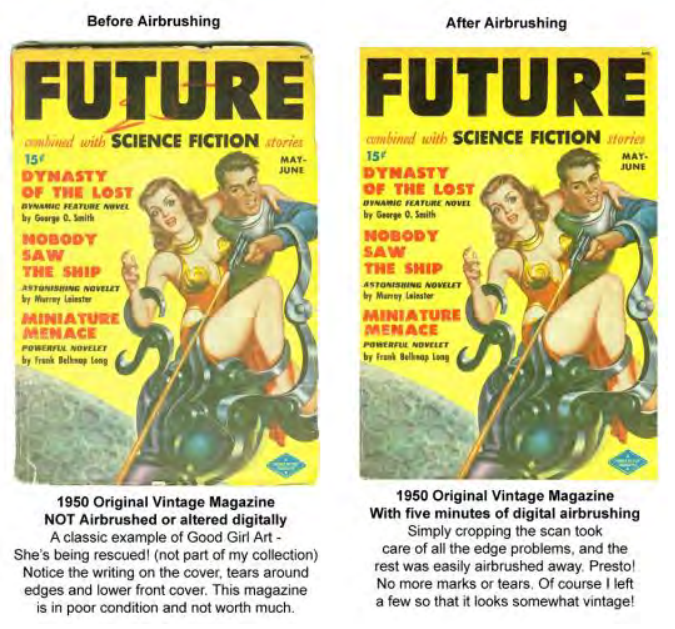

In looking at collections of vintage magazine and book covers, it should be noted that some publishers choose to reproduce the covers -in situ" or exactly as the books are in real life. These publishers will photograph each item from a three dimensional standpoint so that the edges and spine can be seen. Others feel that there is no advantage to the reader to see remainder marks, price stickers, and frayed edges, and so they clean up the book, both physically and digitally. The argument for this approach is that the books will be made to look as close to how they would have when they were new. Whether having vintage books took new" is a good idea or not is a value question that needs not be addressed here.

Cleaning up a book physically often means removing price stickers, which is generally easy to do with some Ronsonol (the lighter fluid), a QTip, and a plastic scraper. That is, unless the stickers are also 50 years old and have completely bonded to the book. On the other hand, removing ink marks is far more difficult because art underneath is often removed along with the offending ink.

For the collection shown here, a conservative approach was taken. It is easy to damage a vintage book, so doing any kind of physical changes to the actual book is counter indicated if the book is rare, unless done by a professional in the field. After all, many of these books are extremely difficult to find, especially in good condition. Take The Grindle Nightmare, for example. It is not the rarest of vintage books, but in searching for a good copy, many of the ones available for sale were in poor condition, presumably because they had been stored in a damp basement, sunny attic, or some other location unfriendly to books. Of course books can also encounter readers unfriendly to books as well. Since most buyers look for copies in Fine or Very Good condition, they're not likely to settle for Poor condition titles unless there are no other options available. For example, it is reasonable to spend a great deal of money for a vintage book in only Good or Fair condition because it was the only copy available. One example is Million Dollar Minx, published in 1965 with a cover painted by well-known cover artist Robert Bonfils. The author on the front is Don Bellmore, a pseudonym of George H. Smith, but interestingly the interior lists Walt Parr as author, an oddity that increases the book's value. 


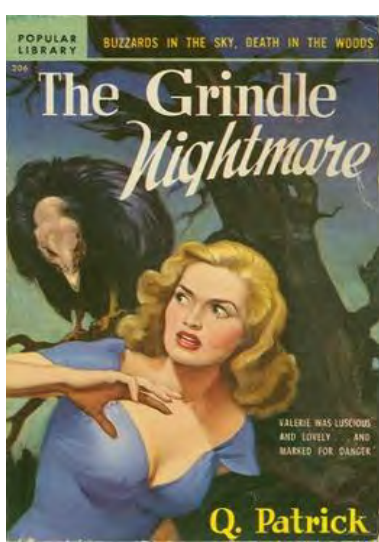

A detailed explanation of these book condition definitions from the Independent Online

Booksellers Association (IOBA) is included at the end of this article. Because these issues vary so much, choices in conserving a collection will depend on the difficulty of the problem, the rarity of the book, and the conservator's skills in caring for damaged books.

Just to be clear however, individuals selling vintage ephemera should not ever airbrush a scan because that would make the item appear to be a higher grade than it actually is, and therefore command a higher price. In other words, that would be fraudulent. The only airbrushing that would be acceptable under these conditions would be that which made a digital scan look more like the original document. For example, adjusting the brightness, contrast, color balance, or sharpening the picture may be necessary if the scanned version does not match the original as well as it might. Part of the reason for this is that graphics on a computer monitor are backlit (by the monitor) so they have a high brightness factor. Ink printed on paper has a very different look than a backlit screen, so adjusting what is seen on the monitor to look more like the original would make sense for a seller to do.

\section{Scanning to Digitize Text and Optical Character Recognition (OCR)}

The other component around scanning images is scanning of the text. All books and other publications printed today are of course already digitized because they were typed into computers when they were written. Vintage products are another story. The back cover of a pulp novel with its accompanying text can be scanned, but the scan in itself is just a picture. If the words are to become accessible and editable as actual text, an application called Optical Character Recognition, or OCR would be run on the scan. The most well known software for this is Nuance Omnipage Pro, however, other applications like $A B B Y Y$

FineReader9 and ReadIRIS are efficient and far less expensive options for most users. ${ }^{1}$

This ability to easily change something once it is digitized, and the result so often not being comparable to the original is why researchers go to the source material whenever possible. For example, when looking for information on say, Rowland Evans, the illustrator and author from Ferrisburgh Vermont (1833-1900), the first stop is likely to be the Stewart-Swift Research Center at the Henry Sheldon Museum in Middlebury. The correspondence collection there includes letters to and from dozens of family members dating from 1760 to 1960, totaling about 20,000 letters. Sadly, these letters are not yet archived online, although they're all listed in the museum's online database by name. Considering the volume of letters, it is understandable why the museum might not have scanned them all in for online access. But researchers can visit the archives which ranks among the top research collections in Vermont.

A trip to look at these letters in person might well be worth the drive because the letters themselves contain other critical information that cannot be gleaned from just looking at a scan (even if access was available online), such as the type and quality of paper and ink, the size and brightness of the product, and many other attributes. These and more are lost when something is transferred to two dimensions - both literally and figuratively.

This strategy can be seen in action in the popular PBS show History Detectives, a popular television show which explores historical mysteries, local folklore, interesting objects that have significance to America's past. Their team uses traditional investigative techniques as well as modern 
technologies, not to mention that they almost always take an original product to a conservator to authenticate it. They do this because identifiers like the age of a document are nearly impossible to validate with a digitized item, and trusting scanned images is only considered dependable under specific conditions.

For example, take a look at Strange Tales; Wolves of Darkness, a -intage" book which is actually a reproduction. It is can be difficult to tell that it is a reproduction when looking at the actual book, not to mention with just the limited information available in a two-dimensional scanned graphic.

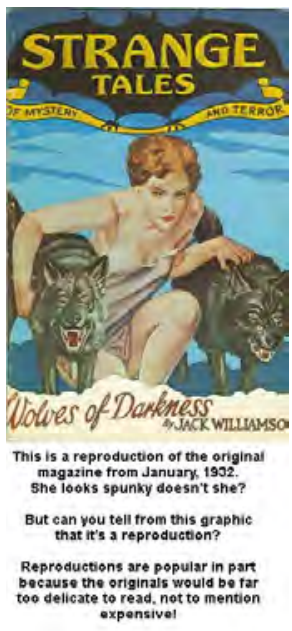

On the other hand, one way to be more confident of the provenance of any product is to know where it came from. The scanned vintage paperback book graphics in this article come directly from the author's collection, and were scanned from those books. Therefore, readers can trust that the graphics seen here are the genuine article.

Unfortunately, that chain of custody for an online graphic is rarely possible, particularly when moving out of the realm of an individual's collection. The United States Government has been grappling with authenticating online documents for many years due to of issues around multiple versions being available simultaneously, as well as the fact that legal documents could be changed by individuals. In the case of a state or federal law for example, this could be disastrous.
The U.S. Government Printing Office (GPO) is working on this issue in three major areas. Here following is an outline of the measures that are recommended for authentication of online documents. ${ }^{2}$

1. Digital Signatures: GPO has begun implementing digital signatures to certain electronic documents on GPO Access that not only establish GPO as the trusted information disseminator, but also provide the assurance that an electronic document has not been altered since GPO disseminated it. The visible digital signatures on online PDF documents serve the same purpose as handwritten signatures or traditional wax seals on printed documents. A digital signature, viewed through the GPO Seal of Authenticity, verifies document integrity and authenticity on GPO online Federal documents, at no cost to the customer.

2. Validation Icons appear next to the GPO Seal of Authenticity to notify users of the content's validity status.

The Blue Ribbon icon indicates that the certification is valid.

The Certification Question Mark icon means that the document was certified, but the validity is unknown. The signer's identity is unknown, because the certificate path could not be built. This icon may appear if a user is not connected to the Internet or if a digital certificate is not available on a user's computer.

The Check Mark icon indicates that the signature is valid.

The Question Mark icon indicates that the signature could not be verified. 
The Warning Sign icon indicates that the document was modified after the signature was added.

The Red "X" icon indicates that the certification is not valid.

\section{National Institute of Standards and Technnology Electronic Authentication Guidelines.}

This recommendation provides technical guidance to Federal agencies implementing electronic authentication. The recommendation covers remote authentication of users over open networks. It defines technical requirements for each of four levels of assurance in the areas of identity proofing, registration, tokens, authentication protocols and related assertions http://purl.access.gpo.gov/GPO/LPS69982

Reference:

Authenticated U.S. Government Printing Office (GPO)

http://www.gpoaccess.gov/authentication/

\section{Part II: Working with an Actual Collection} A Short History of Vintage Magazines \& Books This next section first offers a short history of vintage magazines and books, then focuses on some of the considerations around conservation of those materials.

The Golden Age of magazines encompassed the 1930 s, right around the middle of the depression prior to the war, and those magazines were referred to as "pulps" because they were printed on cheap wood-pulp paper, unlike the more expensive "slicks" which were printed on shiny paper. This paper was so cheap it would sometimes tear going through the presses. These magazines published a variety of fiction including mysteries, westerns, science fiction, men's adventures, romance, horror, sports, railroad and war stories. Western themed magazines, however, dominated the genre with over two thirds of the magazines. What they were known for - and often collected for today - is the sensational cover art.

During the 1940s and with the end of World War II, pulp magazines declined sharply in popularity for a number of reasons, including the paper shortage as well as competition from television and pulp novels. One of the key differences between magazines and novels is that because magazines were published mostly before the mid 1950 s, the cultural sensibility is far more conservative. Pulp novels from the 1960s may be somewhat more liberal in tone, but magazines are far less so. This period is known as the Golden Age of pulp novels, as opposed to the 1930s and prior for magazines. Another key difference between magazines and novels is in the cover style. Although both were designed to grab the attention of passers-by, magazine covers depicted an actual action scene. One look at them and it is clear what the storyline is about. In contrast, book covers - since they needed to express a much larger idea - conveyed an attitude or a feeling. The samples here demonstrate those differences.

\section{Construction and Value}

Pulp magazines, printed on inexpensive pulp paper, had a shorter shelf life to begin with. They were perhaps an early symptom of our throwaway culture, and most were tossed unceremoniously in the trash. The result is that far fewer have survived in good condition compared, for example, to vintage paperback books. Rare pulp magazines in Fine condition can command prices from $\$ 50$ $\$ 100$ and more.

In contrast, paperback books were constructed with better paper and cardboard covers, and if stored in cool dry conditions, can be found in nearly pristine condition today. Readers also often saved books, and the result is that many of these can still be found relatively inexpensively in excellent condition. This translates to an average of $\$ 10-\$ 25$, and $\$ 100$ and up for rare books in Fine condition. This is particularly true since the advent of eBay, an international marketplace which offers far more variety as well as 
competitive prices. Consider however, that any hardcover book printed from the 1950s or even earlier is going to have a much longer shelf life if only because the boards (the outside covers) protected the book much better than the flimsy materials of pulp novels and especially magazines.

\section{Conserving a Collection}

Vintage book collectors often get quite used to seeing these types of books around the house, and because of this, often have to remind themselves that those books on the shelves are more than half a century old. While professional conservators always use white cotton gloves to protect their holdings from the oils in their hands, individual collectors often feel safe enough exercising due caution. Perhaps that's because they believe that part of the pleasure of collecting these items is in the touch and sensual feel of them.

In other words, the visceral experience of cleaning, organizing books is enjoyable in and of itself because of the tangible sensibility of the tasks. Even engaging with the materials of archiving - plastic sleeves, cardboard backings, safe storage boxes, labeling, and more - can be quite pleasurable, particularly to people who enjoy documentation and organization. There is also a great satisfaction in rescuing objects that would otherwise be lost or tossed, not to mention that they are particularly striking when displayed.

There are several levels of book conservation: which individual collectors follow, as well as the professional level found at museums. The issues are the same, the difference is the intensity of the care undertaken. Here are some of the challenges that collectors of vintage ephemera face, although not a complete list:

- Keeping materials dry and away from sunlight, and in moderate room temperature from 60-70 degrees $\mathrm{F}$ and a relative humidity of $45 \%-60 \%$

- Protecting them from insects and other critters

- Preparing for fire, flood, theft and other calamities
- Storing correctly in archival plastic sleeves, with archival cardboard supports if necessary (usually with magazines that are floppy and need the support)

- Shelving and removing appropriately from boxes, files, or bookcases.

- Avoiding use of rubber bands, paper clips, tape and other items that can damage delicate materials

Even with all that to keep uppermost in a conservator's mind, there's nothing quite like the locating the only copy of an especially rare volume and being able to archive it safely. This is particularly true when such a book is received via media mail, in a floppy envelope and swathed in Saran Wrap, surely the nightmare of every conservator.

\section{The Big Picture of Digitization and the Value of Original Collections}

Conservation, while it may relate to digitization and archiving, is generally processed through the minds, hands, and computers of professionals. Ideas cannot by definition become an object that actually smells like it was read long ago by a girl on a porch swing one late autumn evening. Even when an author prints out a product of her mind like this article for example - it has no such sensual appeal. Although, it might if it was allowed to sit around in an attic for fifty years, but then even so, contemporary paper and ink are so much more stable than those used in the 1960s that it is just as likely that this article would be found in near archival condition.

Still, mass digitization is happening on a global scale and at an accelerated pace, particularly as information professionals come to recognize that their actual holdings not only require a great deal of work to keep up, but are not very accessible to anyone outside their immediate physical space. Not to mention that materials online are beginning to be considered de facto research products. That is, even though the Stewart-Swift Research Center may have 20,000 letters of Rowland Evans" family, the fact that researchers have to drive to Vermont to access them is a serious barrier. Not

Education Libraries, Volume 33, Number 2, Winter 2010 
only do most researchers not have the funds of the History Detectives, but spending the time and effort to drive to another state to check out just a few letters would not likely be cost effective for too many researchers. Repeat this one family with this one small collection of materials times thousands of collections around the country, and it is clear why these materials need to be online and accessible.

Across the country organizations like the Google Book Library Project ${ }^{3}$ are digitizing millions of books. This, as elementary teachers used to say, is a transfer of one type of energy into another type of energy with no presumable loss. An interesting aside is that a buyer can purchase any number of books featuring pulp novel covers or stories. Or rather, it is easy to purchase cover and story collections in the form of printed books, digital books like Kindle, or compact disks, which is somewhat ironic. There are hundreds of topic specialties available, from mysteries, science fiction, adventure, sleaze (sexy), western, romance, to romantic westerns, horror, men's adventure, railroad, war stories, sports, and more.

In short, there's no need to buy the actual vintage originals if the collection's focus is simply cover art or stories. But it is important to keep in mind that seeing digital images of these books is not the same as looking at an actual vintage book in your hand. Nor is reading a story from an anthology the same as reading from pulp paper so thin that the pages tan and crackle under your fingertips, whether clad in white archival gloves or not.

There are a limited number of books from the past, particularly those from a specific time period such as a certain decade, which makes contemplating the task of digitizing them not quite so labor intensive. Hundreds of thousands of pulp novels were published, but at least it is possible to say that within any period genre - say romantic westerns - a complete count can be done. Unlike the Google Book Library Project eventually scanning all possible books, a project which is unlikely to be completed even in our grandchildren's lifetimes, it is actually possible to create a database of all the Ranch Romances, for example, if only because there are a limited number of them which is not increasing. This particular series is both one of the most popular as well as the longest running.

\section{About the Author's Collection}

The collection represented here is small for one important reason: it focuses on covers that feature women as protagonists. The vast majority of cover art from this period included women only in what is commonly known as Good Girl Art (GGA), which means that they appear as victims, helplessly waiting to be rescued. By way of contrast, these featured items not only showcase independent women, but many even have guns, popularly known as Gun Molls.

The most interesting group from this collection are the Ranch Romance magazines; the ones shown here originating from the mid 1950s. This series is unique because it consistently depicted women in charge: taking wounded men to safety, watching over the bad guys, and wrestling with an outlaw for her rifle. It is quite clear on some covers that not only are the heroines rescuing themselves, but their men as well. Ranch Romances was the last pulp magazine published in the United States, with issues containing new stories published through the late 1960s, as opposed to the rest of the magazines which went out of publication in the early 1950s.
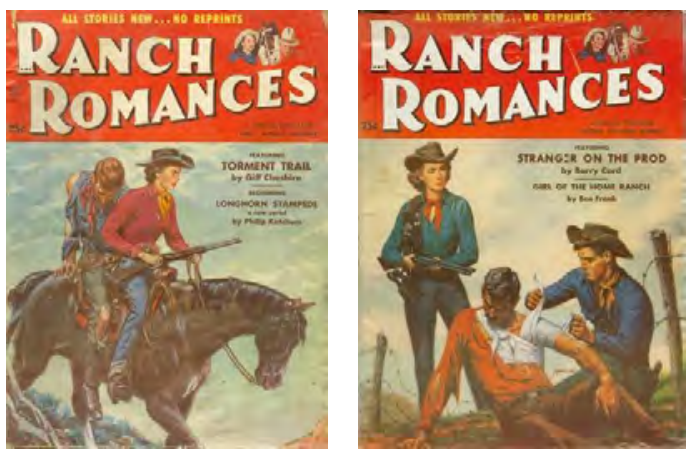

\section{Advantages of Digitization}

Having a few copies of Ranch Romances in a collection is a wonderful thing. But frankly, there aren't too many who have the slightest interest in looking at them, much less hearing about the 
history of vintage paperbacks, conservation, archiving and digitalization. On the other hand, there are thousands of pulp novel and magazine collectors around the world interested in these topics. With the freedom of information available on the Internet, collectors can find each other easily. Still, many websites only include cover scans of vintage products. Cover shots are useful, but they lack a great deal of information for someone researching women's roles in 1950s romantic western publications. For that far more is needed.

Another option would be to take all those Ranch Romances and archive them in an online database. Having content digitized means that the text can be searched and edited, like a Microsoft Word document for example. But more importantly, it usually means that an archivist has taken this information - say this group of magazines - and entered them into a carefully designed database with appropriate tagging. The idea is not that the magazine is simply scanned, run through optical character recognition, and put out on the Internet, although that would certainly be more useful than nothing. To be truly useful to researchers, a search taxonomy that included critical fields such as publication name, date, editor, key stories and authors, and so on would be necessary for a truly useful tool. While it would still not be possible to smell the scent of fifty years of age or listen to the crackle of tanned paper, researchers would have access to critical information.

The key concept here is accessibility; because for delicate ephemera, reading them page by page is a painstaking and tedious process if they are to be kept in their original condition. However, once scanned, both pulp fiction fans and researchers can scour the contents at leisure not least for the unique experience of jumping back in time. Reading the stories does not necessarily reveal the culture of the $1950 \mathrm{~s}$, although they provide information of a certain type - rather, the documents show what publishers could sell in the realm of fiction. Remember that these magazines are A. fiction, and B. fiction about the Old West. So when looking for information about the time period in which the magazines were actually published - in this particular case the 1950s - the content of the actual stories is not going to tell us very much.

The information that is more likely to be found will be literally wrapped around those very stories; in other words, the authors, artists, and publishers names, original illustrations, personals and pen pal classifieds, advice columns, and so much more. The advertisements alone are worth the price of admission, only twenty five cents as noted on the left side of the banner of the Ranch Romances issues.

Who could imagine a reader writing to National Chinchillas of Los Angeles for the opportunity to raise some of these cuties and make $\$ 10,000$ a year? It turns out that $\$ 10,000$ a year is worth somewhere between $\$ 77,000$ and $\$ 332,000$ today according to the Economic History Service calculator ${ }^{7}$, which, aside from the obvious problem with the wide range, is still a pretty good salary for raising a few chinchillas.

\section{WANT $\$ 10,000$ Y SARLY?}

Others make this and more raising Chinchile las. Basement or spare room starts you. We furnish starting stock... buy all you raise. NATIONAL CHINCHILLAS 7372 Melrose Avenue Los Angeles 46, California

For an even more exciting adventure, readers might consider applying to the International Detective Training School in Washington, DC and become a detective. Who knows - it might have been a 1950s version of our colleagues in eompetitive intelligence" or perhaps the predecessors of our History Detectives colleagues on PBS.

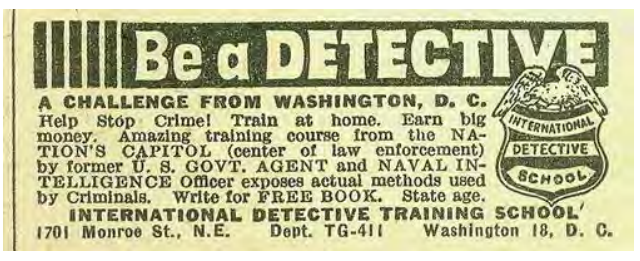

Education Libraries, Volume 33, Number 2, Winter 2010 


\section{A CD of Pulp Art \& Stories: Ready to go for $\$ 15$ a Pop}

Sadly, this type of full archiving is not yet happening with Ranch Romances or any of the common pulp novels or magazines But it is possible to purchase a compact disk which includes 600 stories from the most popular magazines of the 1920s - 1940s such as The Shadow, Doc Savage, and The Phantom Detective. Another CD, with no less than 8000 pulp covers exists, although the scans are small and the resolution is low. This is the result of massive digitalization: cheap pulp paper has turned into cheap digital resolution. It is also possible to find most of these pictures for free on the Internet with a little online research. What does a buyer get for $\$ 15$ then? They get the convenience of having had someone collect all that material, which is a pretty good deal, even if it is not searchable in any practical fashion.

\section{A \$15 CD Won't Cut It for Professional Use}

The critical part of digitization of archival materials is not in the fact or not of a compact disk of 8000 cover scans. Products like that are for personal use, because anyone who is using these covers for professional use would need high resolution scans directly from the original books, not unlike the ones in this article. In other words, for professional publication, or even if it is just necessary to see any significant detail, a four-inch, low resolution scan is too small.

Furthermore, having a compact disk of 600 stories may be fun for personal use, but without a taxonomy and well-built search engine, researchers would find it all but useless. In short, just digitizing information is not enough. It must be transformed into a well-planned format that allows researchers to access the part that they need.

While these dreams of a pulp collection being fully archived and full-text accessible in some database may be some years away, there are plenty of other important collections of ephemera that are, and those are more likely the ones librarians will and are using in their ongoing research.

\section{Copyright Issues and Vintage Products}

Because of this mass proliferation of materials, a digital scan on the internet defaults in a way to public property - copyright laws notwithstanding. This is not speaking from a legal standpoint, just from a practical one; one of looking straight out there at 8000 scans on a compact disk for $\$ 15$, and knowing that there is no one who cares, much less wants to sue the sellers of that CD. All of this comes under the big shade tree of Orphaned Works which is a whole legal area of its own. In any case, the copyright laws on these particular books are something of a mystery themselves because of the time period and the fact that all of the publishers are out of business. Aside from Greenleaf, who was the largest pulp publisher of them all; the vast majority of publishers particularly of pulp novels - were fly-by-night.

To make things even more complicated, the artists are almost all unknown because of the art not being signed and the issues discussed earlier, not to mention that many of them have passed away. The result is that it is nearly impossible to get reprinting permission either for content or for covers, which explains why reproductions of both are pervasive throughout the internet.

\section{A Few Examples of Online Digitization}

Any researcher who accesses the Internet, has also accessed some digitized content. Perhaps it was on Amazon.com while looking up Jane Greenfield's ' The Care of Fine Books and selecting - Click to look inside." Inside there's an excerpt which details the nature and history of books and how they were made in the early days. That excerpt is the result of someone having digitized this book, or rather transferred the original digital file to Amazon in the first place. That's the most basic type of digitization, because all new books are typed into a computer these days.

Utah Digitizes their Newspapers Back to 1850 Consider that the Utah Digital Newspapers program has scanned more than six million 
articles from 1850 to 1969 . Just imagine the wealth of information available to a researcher in Utah or in fact anywhere in the world. More importantly, this project is just one of thousands happening across the country in the newspaper industry, and there are many more thousands among other organizations of other ephemera: photographs, letters, and more.

\section{Educational Testing Service's Database of Materials all the Way Back to 1948}

Every researcher at one time or another has done an internet search and dredged up something deep in some database somewhere that they didn 't even know existed. This happened to the author of this article when she went hunting for articles that her father, Charles Earl Werts, wrote before he passed away. Thanks to the historical database of the internet, the search revealed the mother lode of his published papers at the Educational Testing Service (ETS) ReSEARCHER database which contains more than 3,300 of their documents since 1948. ETS is the folks who create the SATs each year, and also where he worked when the family was growing up in Princeton, New Jersey.

Dr. Werts penned academic treatises on research statistics, but a few articles were found on surprisingly relevant and immensely personal (in retrospect) subjects of parental influence on talent development. These were written in 1972, just about the time when her older sister was leaving high school for college and the writings indicated that sons and daughters excel in particular skills that the father uses in his occupation.

A side note of interest is that one of our Education Libraries Review Board Members Karen McQuillen is the manager of Brigham Library at ETS. Karen has included in this issue an article on the Test Collection at ETS that she wrote for Education Libraries back in 1975 as well as an update on the collection as it is managed now.

\section{The National Park Service's Collection}

\section{Preservation Series}

Finally, researchers interested in conservation might run into the Conserve-o-Gram: Planning
Digital Projects for Preservation and Access, one of over a hundred documents the National Park Service Department of the Interior (a perhaps surprising source), publishes which are not only well written, well organized, and complete - but free. This particular document details how to manage a digitization project including some of the major areas such as system capabilities, staff expertise, collection stability, and so on. It is part of the Archival and Manuscript Collections and Rare Books series which includes over 20 topic areas from Care and Security of Rare Books to Storing Archival Paper-Based Materials. From one small document this, and even more from an organization one never would have looked to first for such a complete and consistent set of documents on museum collection preservation of every possible material. It is these kinds of finds that researchers would not have been able to locate much less use before fully digitized materials came on online.

Considering the state of global warming something the National Park Service is presumably well aware of - on behalf of Mother Nature, please consider reading the digital version of these articles.

\section{In the End it It's Still about the Books}

What sometimes gets lost in all this talk about archiving our history is that reading is not just about books. The act of reading was then as it is now, a sublime and sensual experience that cannot be digitized entirely no matter how it is scanned. Many of these magazines and books were considered a wee bit subversive, or at least not educationally edifying like a good book on the discovery of America (or the re-discovery as it is recognized to be these days). Contemporary readers would not find these books very racy by today's standards; in fact they'd probably laugh at what was considered madcap back in the 1960s, particularly before the censorship code was radically relaxed in the latter part of the decade.

As a librarian, a conservationist, a researcher and more, it is not just a duty, but a gift to steward the actual holdings - those books, photographs, letters 


\section{What do we Gain and Lose from Digitizing Ephemera? Gains \\ Losses}

Full accessibility to everyone!

Allows for close and extended observation of materials without physical damage to delicate originals

Full text and photo search

Awareness of topical areas which were often not well known - such as narrow genre collections of vintage paperbacks
Original files can be easily edited or airbrushed

Distribution of content and images can't be limited (it is extremely difficult anyhow)

Digital versions cannot convey the sensual experience of the original product

Difficulty in identifying provenance because the link to the original item is easily lost.

Specifics such as paper and ink type, age and other descriptors are unavailable

It is hard to cuddle up with it before bed! 


\section{$I B \mathrm{BA}^{\prime \prime}$}

\section{Independent Online Booksellers Association (IOBA) Book Condition Definitions}

These book condition definitions are used to describe both the book and the dust jacket, if applicable. Thus the word -book-may be replaced by -dust jacket-in the following definitions:

As New; Fine; Mint: Without faults or defects.

NEAR FINE: a book approaching FINE (or AS NEW or MINT) but with a couple of very minor defects or faults, which must be noted.

NOTE: From here on, there may be "+ (Plus)" or "- (Minus)" in a grade, which will mean that it is above the grade noted but not quite to the next higher grade for "+", and that it is below the grade noted but not quite to the next lower grade for "-", i.e., Very Good + (or Plus)/Very Good - (or Minus). Which means the book is better than Very Good and the dust jacket grade is less than Very Good.

Very Good: A book showing some signs of wear. Any defects or faults must be noted.

Good: The average used book that is totally complete (as issued) and intact. Any defects must be noted.
Fair: A worn book that has complete text pages (including those with maps or plates) but may lack endpapers, half-title page, etc. Any defects or faults must be noted.

Poor or Reading Copy: A book that is sufficiently worn that its only merit is the complete text, which must be legible. Any missing maps or plates must be noted. May be soiled, scuffed, stained, or spotted, and may have loose joints, hinges, pages, etc.

Ex-Library: Must always be designated as such no matter what the condition of the book.

Book Club: Must always be noted as such no matter what the condition of the book.

Binding Copy: A book in which the text block, including illustrations, is complete but the binding is lacking, or in such poor condition it is beyond realistic restoration efforts.

\section{The Independent Online Booksellers Association (IOBA) is dedicated to promoting Internet bookselling by:}

1. Maintaining and enforcing high ethical and professional standards for our member booksellers, including a Code Of Ethics.

2. Promoting trust between customers and booksellers by providing a safe online environment for the purchase and sale of books.

3. Negotiating with businesses, organizations, and possibly governmental agencies that have an impact on internet bookselling.

4. Marketing to consumers to raise awareness of online bookselling,

5. Providing services and programs that will help member booksellers strengthen their businesses.

Reprinted with permission from the Independent Online Booksellers Association (IOBA) http://www.ioba.org/ 


\section{Resources \& References}

Extensive References can be found on the author's Delicious.com Research Bookmarks including:

- Websites specializing in a variety of Pulp Genres

- Archiving and Conservation

- Online Vintage Paperback Sellers

- Books on Pulp Magazines and Novels

- Artist and Author websites

- Vintage book search engines

- Materials/Companies for archiving

http://delicious.com/SuperTechnoGirl

See more of the author's Pulp Novel Collections

http://www.flickr.com/photos/29468613@N08/collections/72157608112299861/

\section{Endnotes}

${ }^{1}$ OCR Software Guide from ScanStore: Comparison of OCR Applications. (2008). Retrieved October 27, 2008, from ScanStore Web site: http://www.scanstore.com/Scanning_Software/OCR/

${ }^{2}$ Authentication. (2008). Retrieved October 27, 2008, from U.S. Government Printing Office (GPO) Web site: http://www.gpoaccess.gov/authentication/

${ }^{3}$ Google Books Library Project. (2008). Retrieved October 27, 2008, from Google Book Search Bet Web site: http://books.google.com/googlebooks/library.html

${ }^{4}$ Werts, Cybèle Elaine (2007). Interview with Rose Idlet of Black Ace Books. from http://www.blackace.net/

${ }^{5}$ Interview with George H. Smith. (2008). Authors Den, Retrieved October 23, 2008, from http://www.authorsden.com/visit/author.asp?authorid=3134

${ }^{6}$ McDonald, Jamie, Director (2005). DVD: Pulp Fiction Art. Retrieved October 23, 2008, from the DVD available from http://www.pulpfictionart.com/

${ }^{7}$ Measuring Worth. Retrieved October 27, 2008, from EH.net (Economic History Service) Web site: http://www.measuringworth.com/uscompare/

\section{Other Resources}

\section{Articles by Charles Earl Werts (Cybèle's Father)}

Paternal Influence On Talent Development - By Werts, Charles E.; Watley, Donivan J.

Journal of Counseling Psychology. Vol 19(5), Sep 1972, 367-373. \$11.95

Grouped 127,125 college freshmen by father's occupation. Father's occupations were then compared in terms of the probability of the sons and daughters having attained various types of achievements (scientific, artistic, oral, leadership, musical, and literary) in high school. Results indicate that sons and daughters excel in particular skills the father uses in his occupation. (PsycINFO Database Record (c) 2008 APA, all rights reserved)

http://psycnet.apa.org/index.cfm?fa=buy.optionToBuy\&id=1973-03348-001

\section{Paternal Influence On Career Choice - By Werts, Charles E.}

Journal of Counseling Psychology. Vol 15(1), Jan 1968, 48-52. \$11.95

Fathers' occupations were compared with sons' career choices for 76,015 male college freshmen. The results indicated that for sons of professionals, the occupational groupings on the SVIB are useful in describing broad types of "inherited" occupations. (PsycINFO Database Record (c) 2008 APA, all rights reserved) http://psycnet.apa.org/index.cfm?fa=buy.optionToBuy\&id=1968-06195-001

\section{EH.net (Economic History Service)}

Have you ever wondered what the "worth" of a (US) dollar or a (British) pound was in 1907? Or what something purchased years ago with pounds would be worth in dollars today? These and a multitude of other questions can be answered using these calculators.

http://www.measuringworth.com/uscompare/ 
Six Ways to Compute the Relative Value of a U.S. Dollar Amount. Current data is only available till 2007. In 2007, $\$ 10,000.00$ from 1955 is worth:

$\$ 77,424.20$ using the Consumer Price Index

$\$ 64,043.08$ using the GDP deflator

$\$ 107,508.53$ using the value of consumer bundle

$\$ 103,219.70$ using the unskilled wage

$\$ 182,172.18$ using the nominal GDP per capita

$\$ 332,871.26$ using the relative share of GDP

*Calculated October 2, 2009

\section{Educational Testing Service (ETS) ReSEARCHER}

A database that contains abstracts for ETS research publications, including ETS Research Reports and Research Memorandums. More than 3,300 such documents have been published since 1948.

http://search.ets.org/custres/

\section{History Detectives on PBS}

History Detectives is devoted to exploring the complexities of historical mysteries, searching out the facts, myths and conundrums that connect local folklore, family legends and interesting objects. Traditional investigative techniques, modern technologies, and plenty of legwork are the tools the History Detectives team of experts uses to give new - and sometimes shocking - insights into our national history.

Their Investigative Techniques page includes topics on Document Examination: Testing documents identifies forged and authentic papers, as well as Paper Analysis: Determining age, make-up and origin.

http://www.pbs.org/opb/historydetectives/

\section{National Park Service Conserve-o-Grams}

Conserve-o-Grams are short, focused leaflets about caring for museum objects, published in loose-leaf format. This is a selected list of documents that might be of interest to readers.

\section{Archival and Manuscript Collections and Rare Books}

19/1 What makes a Book Rare? 1993

19/2 Care and Security of Rare Books 1993

19/3 Use and Handling of Rare Books 1993

19/4 Archives: Preservation Through Photocopying 1993

19/5 Removing Original Fasteners from Historic Documents 1993

19/6 Attachments for Multi-Page Historic Documents 1993

19/7 Archives: Reference Photocopying 1993

19/8 Preservation of Magnetic Media 1993

19/9 Caring for Blueprints and Cyanotypes 1995

19/10 Reformatting for Preservation and Access: Prioritizing Materials for Duplication 1995

19/11 Preservation Reformatting: Selecting a Copy Technology 1995

19/12 Contracting for Reformatting of Photographs 1995

19/13 Preservation Reformatting: Inspection of Copy Photographs 1995

19/14 Judging Permanence for Reformatting Projects: Paper and Inks 1995

19/15 Storing Archival Paper-Based Materials 1996

19/16 Housing Archival Paper-Based Materials 1996

19/17 Handling Archival Documents and Manuscripts 1996

http://www.nps.gov/history/museum/publications/conserveogram/cons toc.html

\section{Rowland Evans and the Rokeby Museum}

For more information on Rowland Evans (1833-1900), the illustrator and author from Ferrisburgh Vermont http://www.rokeby.org/home.html 


\section{Stewart-Swift Research Center at the Henry Sheldon Museum}

Rowland Evans' letters are stored and available for research here, although not archived online. (too bad!)

http://www.henrysheldonmuseum.org/research_ctr.html

Utah Digital Newspapers - Funded by the Institute of Museum and Library Services and the Library Services and Technology Act

The digitized newspapers in this website may be browsed by issue or searched by keywords, article titles, weddings, deaths, and births.

http://ebb.lib.utah.edu/digital/unews/

\section{Pulp Art Preservation Projects}

Bowling Green State University Popular Culture Library

Archives include over 10,000 volumes of popular fiction in addition to 10,000 periodical issues. Strengths are

American magazines (1926-1960), pulps, and fanzines. Approximately 1,000 items are added annually.

http://www.bgsu.edu/colleges/library/pcl/

\section{Michigan State University Special Collections Division}

Houses the Russel B. Nye Popular Culture Collection which contains material from the following genres: juvenile, detective-mystery, science, western, and women's fiction. In addition, the archive includes many dime novels, story papers, and pulp magazines that fall into none of these clearly delineated genre headings.

http://www.lib.msu.edu/coll/main/spec col/nye/

\section{Stanford University Penny Dreadfuls \& Dime Novels Collection}

Consists of over 8,000 individual items, including long runs of the major dime novel series and holdings of story papers like the New York Ledger and Saturday Night. The digital collection is searchable by title, feature, or image and includes a guided tour and a time line.

http://www-sul.stanford.edu/depts/dp/pennies/home.html

\section{Syracuse University Street \& Smith's Preservation and Access Project}

Houses the Street and Smith Publishing Company Archive which includes corporate records, manuscripts, radio scripts, serials, and dime novels. The preservation and access project will include microfilming 1,000,000 pages of material from the Archive.

http://libwww.syr.edu/digital/guides/s/StreetAndSmith/

\section{State University of New York at Buffalo Pulp Fiction Preservation Project}

The George Kelley Paperback and Pulp Fiction Collection is comprised of over 25,000 pulp fiction books and magazines. Dr. George Kelley donated the collection to Lockwood Library in 1994.

http://libweb.lib.buffalo.edu/kelley/

Cybèle Werts lived in Massachusetts, and was former co-editor of Education Libraries. Cybèle passed away in October 2010. 